\title{
TÊMPERA DE AÇO SAE 1045 UTILIZANDO DIFERENTES MEIOS DE RESFRIAMENTO*
}

Renato Pereira da Silva Junior ${ }^{1}$ Guilherme Cogo Biazotto ${ }^{2}$ Jan Vatavuk ${ }^{3}$ Leonardo Calicchio ${ }^{4}$

\section{Resumo}

Soluções poliméricas são uma alternativa para meio de resfriamento com coeficientes de extração de calor intermediários ao da água e do óleo. Pode resultar em uma severidade menor em relação à tempera em água e uma menor emissão de poluentes, maior penetração da tempera e maior segurança em relação à tempera em óleo. 0 objetivo deste trabalho é analisar a influência da solução aquosa com $0,03 \%$ de Álcool Polivinílico (PVA) como meio de resfriamento para o aço carbono SAE 1045, comparando-se os resultados de microestrutura e dureza do aço SAE 1045 como recebido e após tratamento térmico de têmpera nos meios de resfriamento: água, óleo e salmoura.

Palavras-chave: Têmpera; Meios de resfriamento; SAE 1045; Álcool polivinílico.

\section{QUENCHING ON STEEL SAE 1045 USING DIFERENTS QUENCHANTS}

\begin{abstract}
Polymer solution is an alternative to quenchant with heat extraction coefficient in the middle of water and oil. Could results in less quench severity than water quenching and a less pollution emission, larger quenching layer and a more security than the oil quenching. The goal of this paper is analyse the solution of $0,03 \%$ PVA as quenchant to the SAE 1045 steel, comparing the results of microstructure and hardness of the raw steel and after quenching water, oil and salt solution.
\end{abstract}

Keywords: Quenching; Quenchant; SAE 1045; Pollyville alcohol.

1 Formando no curso de Engenharia de Materiais da Universidade Presbiteriana Mackenzie, São Paulo, SP, Brasil.

2 Aluno do curso de Engenharia de Materiais da Universidade Presbiteriana Mackenzie, São Paulo, SP, Brasil.

3 Professor Doutor da Escola de Engenharia da Universidade Presbiteriana Mackenzie, São Paulo, SP, Brasil.

4 Professor Mestre da Escola de Engenharia da Universidade Presbiteriana Mackenzie, São Paulo, $S P$, Brasil. 


\section{INTRODUÇÃO}

As propriedades mecânicas de um aço estão diretamente ligadas à sua microestrutura, que influencia na dureza, ductilidade, resistência mecânica e tenacidade. As diversas aplicações possíveis para um aço, requerem diferentes combinações de características, que são possíveis de serem obtidas através de tratamentos que alterem as propriedades do aço, tornando mais efetiva e segura a sua aplicação. Tratamentos térmicos, como o de têmpera, são usados em larga escala para alterar a microestrutura e propriedades do aço para sua aplicação desejada. Características distintas são consequentes de acordo com a taxa de transferência de calor entre a peça e o meio resfriamento aplicado no tratamento. O objetivo principal da têmpera é aumentar a dureza e a resistência mecânica do aço, elevando-se a temperatura do aço para transformar sua estrutura em austenita, seguindo de resfriamento brusco, resultando na estrutura martensítica. A martensíta, uma fase metaestável supersaturada de carbono, devido à sua transformação por cisalhamento, modifica o reticulado cristalino gerando tensões internas. Os meios de têmpera mais comumente utilizados são água, óleo, salmoura e, mais recentemente, soluções poliméricas, cada um com características específicas e seu uso depende do resultado final desejado para a peça tratada. Por apresentar taxas de transferência de calor intermediarias ao óleo e à água, o meio de resfriamento em solução polimérica é o principal objeto de estudo deste trabalho, além de proporcionar um melhor controle da transferência de calor, resulta em menos tensões internas, se comparado a água e menos emissões de poluentes, se comparado ao óleo. [1].

O processo de têmpera e aquecimento dos aços está diretamente relacionado a densidade do fluxo de calor. Vários fatores influenciam no mecanismo de têmpera do metal processado. Condições internas à amostra afetam a difusão de calor e a superfície da amostra e outras condições externas podem afetar o potencial de extração de calor do fluído, como: agitação, pressão e temperatura de trabalho dos fluídos. [2].

A severidade do tratamento térmico se refere à habilidade do fluído na extração de calor do aço aquecido. Quanto maior a severidade do meio maior será a distorção da peça. Existem representações quantitativas da severidade que presumem um coeficiente de transferência de calor constante em todo o processo de resfriamento, 0 que muitas vezes não é verdade. Quando utilizados meios de tempera como óleo e água, por exemplo, ocorre vaporização da solução, modificando o mecanismo de resfriamento do aço. Forma-se uma bolha de vapor que impede o fluxo de calor natural, sendo assim, o coeficiente de transferência de calor será diferente nesse momento, resultando em heterogeneidade na extração de calor. Diversos testes já foram realizados para determinação experimental de um coeficiente mais preciso, elaborando-se cálculos e métodos. [3].

A opção tradicional para evitar a severidade da água, como meio de tempera, é a utilização do óleo mas, em alguns casos, este pode ser inadequado para a aplicação não resultando nos valores de resistência mecânica desejados. As taxas de extração de calor de soluções poliméricas normalmente são intermediárias as do óleo e da água, sendo a sua principal vantagem a redução de emissões poluentes provenientes de hidrocarbonetos que compõem os óleos de petróleo. Estas soluções poliméricas são usadas como meios de tempera há mais de 50 anos e são compostas de polímeros solúveis em água. [2]. 


\section{MATERIAIS E MÉTODOS}

Para os ensaios foram cortadas amostras de $60 \mathrm{~mm}$ de uma barra de aço SAE 1045, trefiladas e com $7,9 \mathrm{~mm}$ de diâmetro, visando uma geometria que proporcionasse à seção transversal, no centro longitudinal da peça, condições de tratamento sem influências dos efeitos de ponta do material. Para maior reprodutibilidade possível nos ensaios foi elaborado um dispositivo para inserção dos corpos de prova com máximo paralelismo ao meio de têmpera. Os diferentes meios de têmpera foram acondicionados em um béquer, conforme a Figura 1.

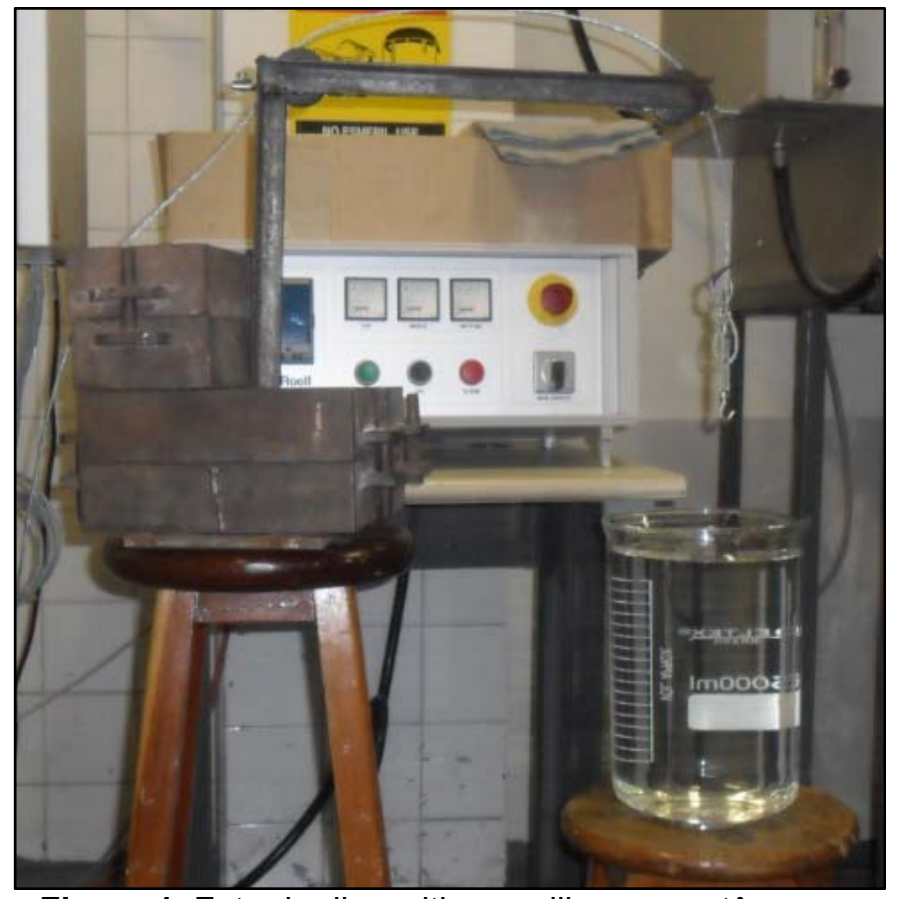

Figura 1. Foto do dispositivo auxiliar para a têmpera.

Os corpos de prova foram previamente amarrados com arame para sua prática remoção do forno e, através de um encaixe circular posicionar o suporte no gancho do dispositivo para sua inserção no meio de têmpera.

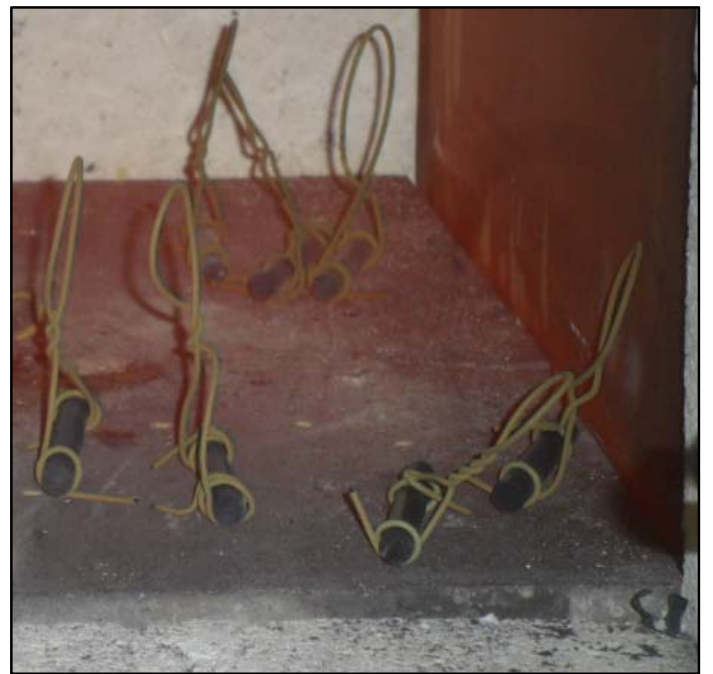

Figura 2. Foto dos corpos de prova amarrados com arame. 
As amostras foram aquecidas em forno Brasimet do tipo Mufla, sem atmosfera controlada. O pré-aquecimento foi efetuado à $940^{\circ} \mathrm{C}$ para garantir a completa austenitização e que, após a retirada do forno, o contato com o ar ambiente não proporcionasse transformação da austenita de forma indesejada.

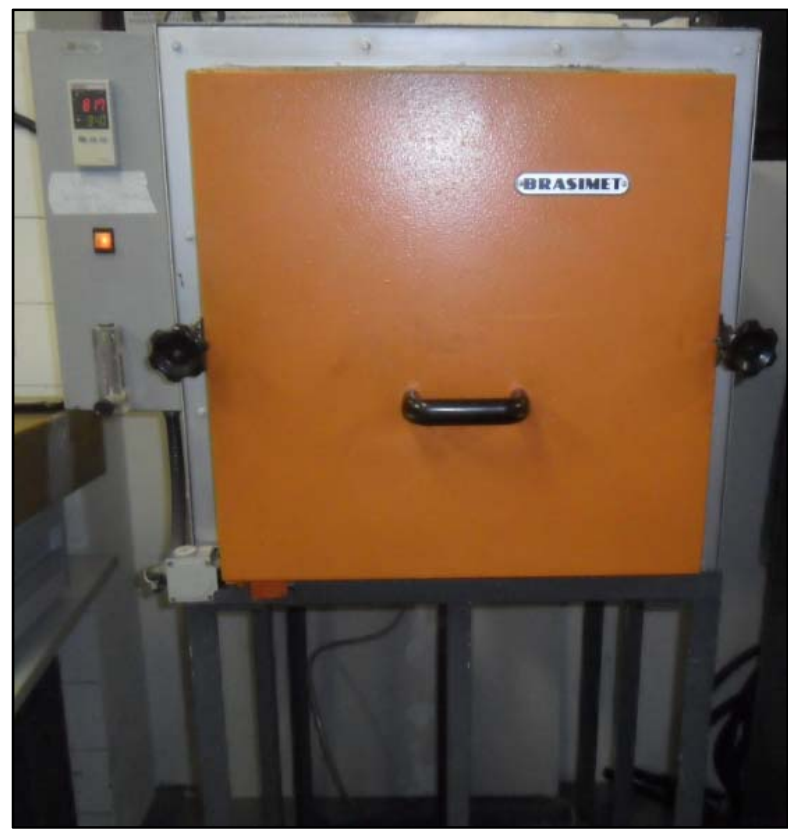

Figura 3. Forno Brasimet do tipo Mufla.

Os corpos de prova permaneceram no forno por 30 minutos após serem inseridos para garantir a transformação de fase no núcleo da peça. Todas as amostras foram retiradas do forno com auxílio de um tenaz e posicionadas no gancho do dispositivo para inserção contínua no meio de têmpera, permanecendo no meio até o seu completo resfriamento.

Tabela 1. Meios de têmpera utilizados

\begin{tabular}{|c|c|}
\hline Água & Água de Torneira sem aditivos \\
\hline Óleo & Óleo mineral sem aditivos \\
\hline Salmoura & Concentração de $150 \mathrm{~g}$ sal / Litro de água \\
\hline Solução Polimérica & 0,03\% de Álcool Polivinílico em água \\
\hline
\end{tabular}

Todos os meios de têmpera foram utilizados em temperatura ambiente e sem agitação, para comparação da influência da formação do filme de vapor sem interferências externas. Na troca dos meios de têmpera o béquer foi corretamente higienizado visando a não contaminação de resíduos de um meio em outro.

Para metalografia, os corpos de prova foram embutidos, lixados e polidos para posterior ataque com Nital à concentração de $2 \%$, durante 5 segundos.

As medidas de dureza foram realizadas em durômetro Rockwell, nas escalas B e C, e os resultados foram convertidos para a escala Brinell para melhor comparação. 


\section{RESULTADOS E DISCUSSÃO}

\subsection{Microestruturas}

Na sequência, fotos da metalografia das amostras temperadas nos diferentes meios de resfriamento apresentados e também da amostra de material pré-tratamento, todas as fotos realizadas em Microscópio ótico com aumento de 500 vezes.

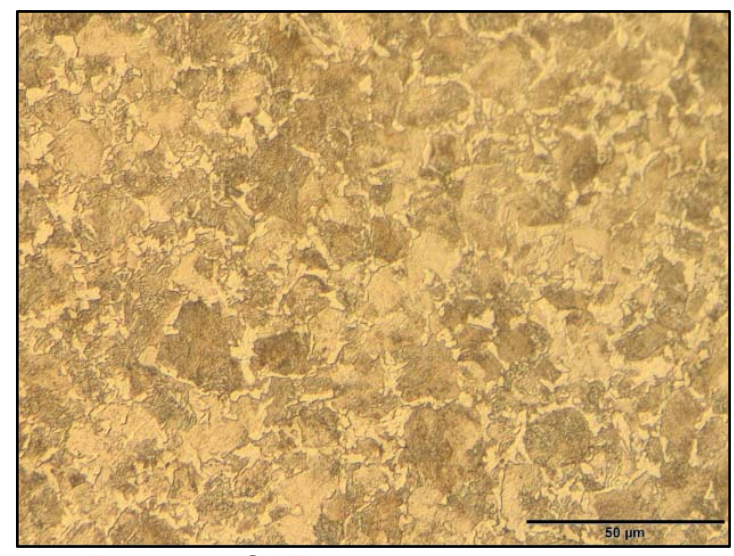

Figura 4. SAE 1045 sem tratamento.

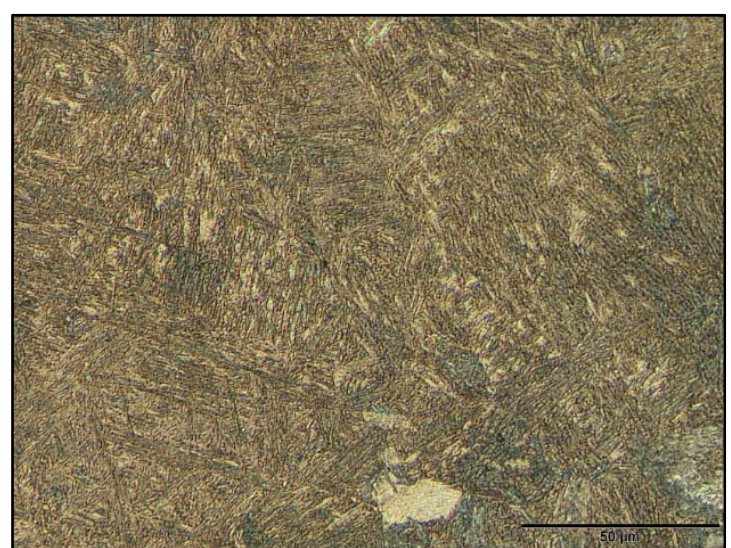

Figura 5. SAE 1045 têmpera em Salmoura.

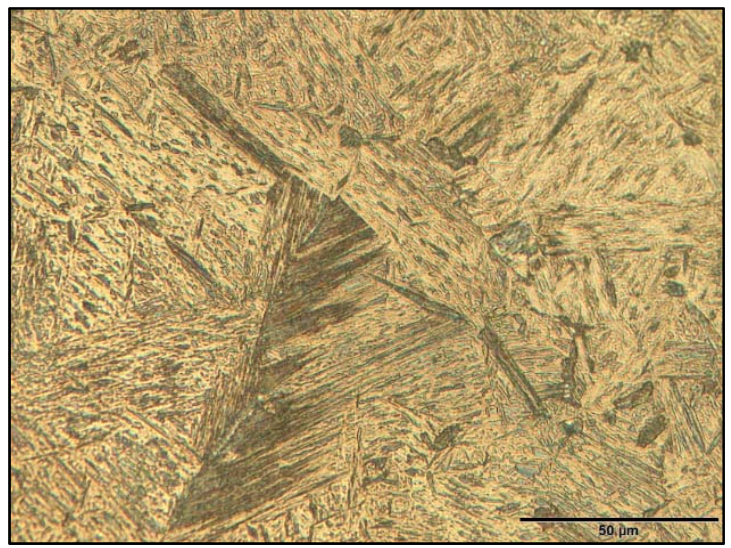

Figura 7. SAE 1045 têmpera em Sol. PVA.

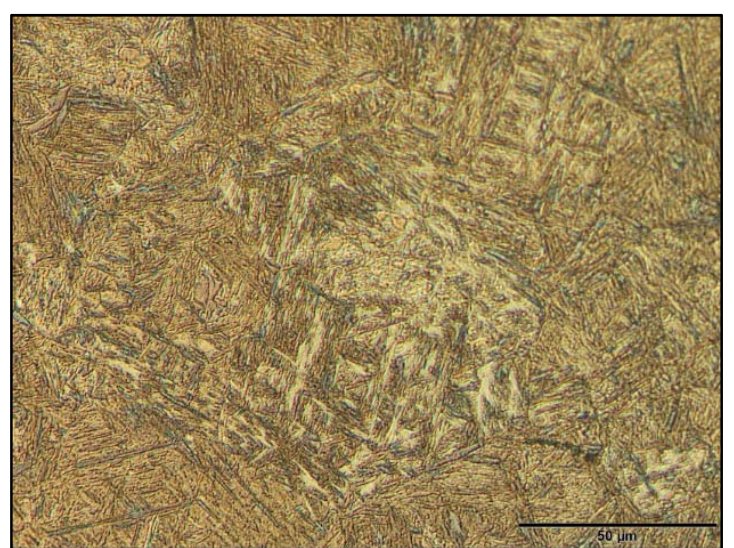

Figura 6. SAE 1045 têmpera em Água.

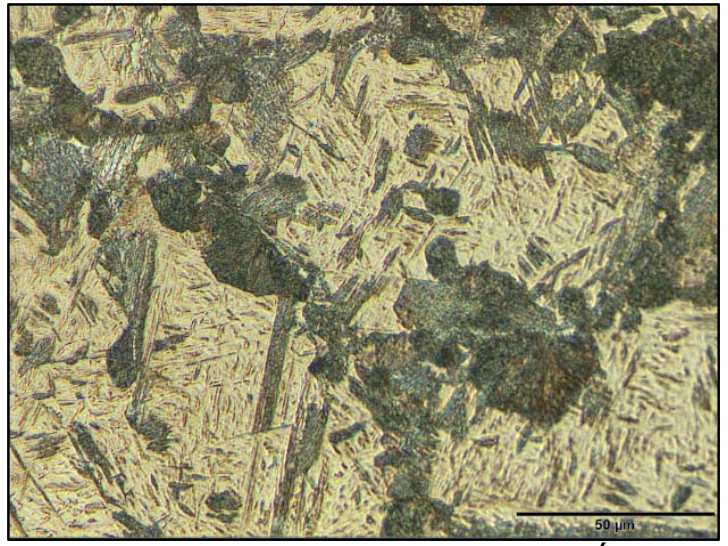

Figura 6. SAE 1045 têmpera em Óleo. 
Observa-se na Figura 4 uma estrutura característica de aço com 0,45\% de Carbono, com lamelas de perlita fina consequentes de uma normalização, ainda que não intencional, nos processos anteriores de conformação da barra trefilada.

A Figura 5 exemplifica intensa presença de agulhas de martensíta, provenientes do severo resfriamento na solução de salmoura, como esperado.

$\mathrm{Na}$ Figura 6 observamos uma estrutura convencional para um aço SAE 1045 temperado em água, com as agulhas de martensíta dispersas em uma matriz ferrítica. A Figura 8, têmpera em óleo, apresenta o microconstituinte bainita disperso entre grãos de perlita em uma matriz ferrítica, onde também se pode observar a presença de algumas agulhas de martensíta. Uma metalografia rica em microconstituintes, demonstrando a influência do meio na curva TTT.

Por fim a Figura 7, têmpera em solução de PVA $(0,03 \%)$, objeto deste estudo, nos mostra uma clara transformação da microestrutura em bainita. $\mathrm{O}$ aço nessa condição de têmpera, resultou em uma microestrutura intermediária à da água (preponderante em martensíta) e à do óleo (com expressiva presença de perlita e bainita), como proposto.

\subsection{Dureza Rockwell}

Abaixo a média de cinco medidas de dureza realizada para cada corpo de prova.

Tabela 2. Resultado das medidas de dureza

\begin{tabular}{|c|c|c|c|}
\hline \multicolumn{1}{c}{ Amostra } & \multicolumn{2}{c}{ Rockwell } & \multicolumn{2}{c}{ Brinell } \\
\hline Sem tratamento & RB & 99 & 235 \\
Têmpera em óleo & RC & 39 & 362 \\
Têmpera em Sol. PVA & RC & 50 & 481 \\
Têmpera em água & RC & 53 & 525 \\
Têmpera em Sol. Sal & RC & 45 & 421 \\
\hline
\end{tabular}

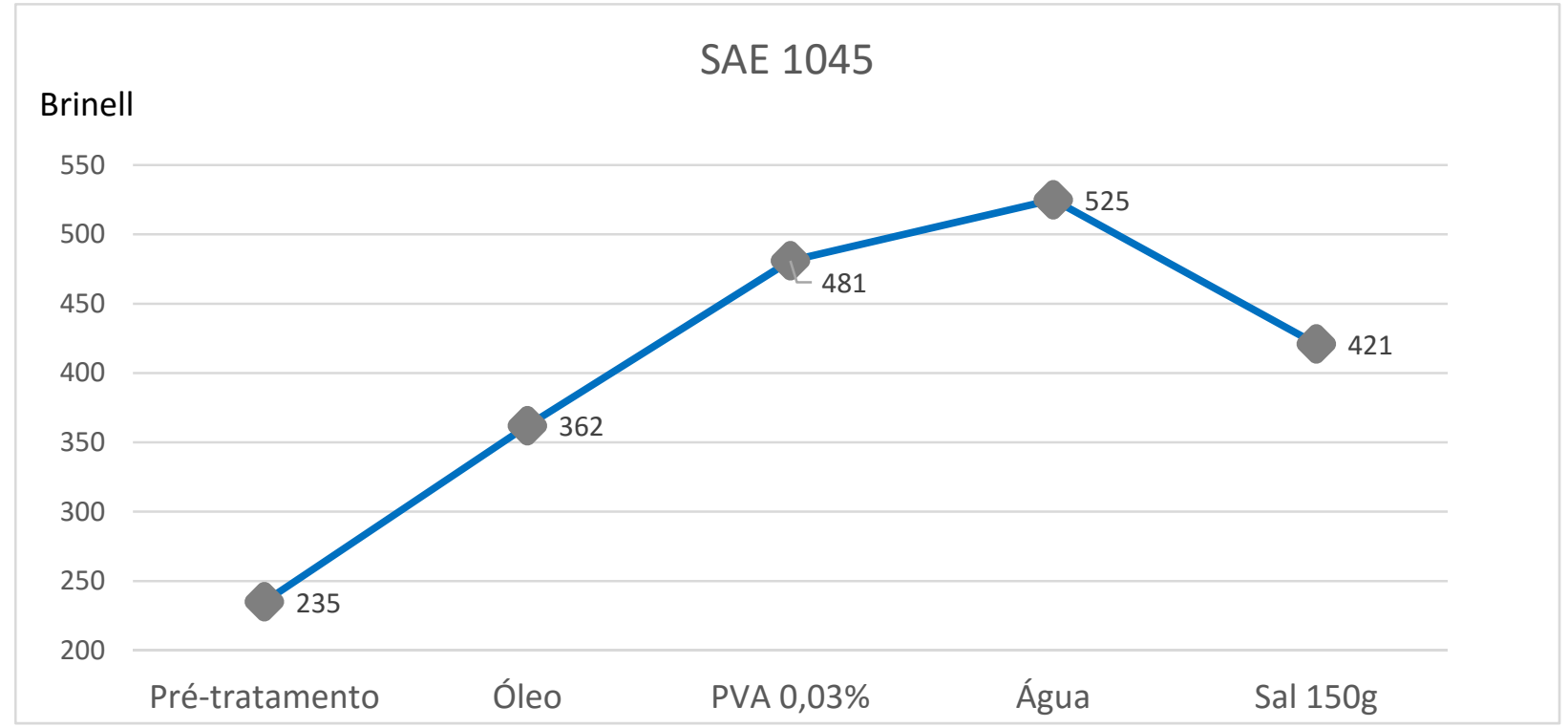

Gráfico 1. Dureza média para o aço SAE 1045 nos meios de têmpera estudados. 
As medidas de dureza para a amostra temperada em Salmoura foram inferiores aos da amostra temperada em água e mesmo aos da amostra temperada na solução polimérica, conforme o Gráfico 1. Este resultado permite concluir que o ensaio realizado em salmoura não foi representativo para este estudo. Na Figura 9, observase em detalhe a expressiva formação de carepa no corpo de prova que reduziu o contato do meio de tempera com o aço, evitando que o potencial de extração de calor da salmoura tivesse efeito.

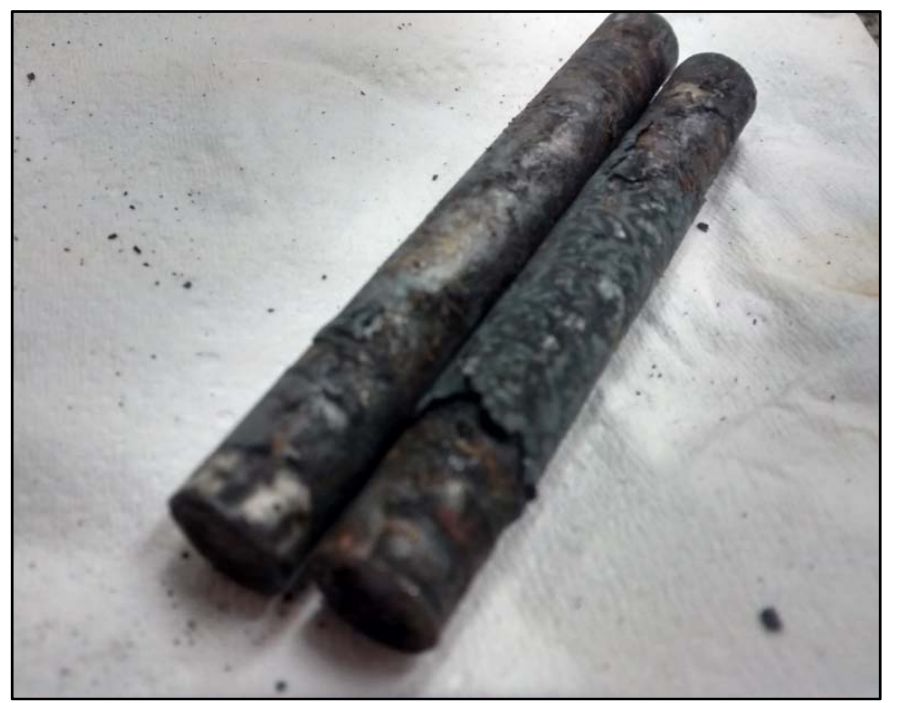

Figura 9. Carepa formada na amostra após ser submetida à têmpera em salmoura.

\section{CONCLUSÃO}

O estudo comprova que a solução polimérica realmente apresenta resultados intermediários aos da água e do óleo. Através da análise das metalografias observase que mesmo em pequenas concentrações a presença de Álcool Polivinílico pode modificar significativamente o comportamento do meio de têmpera, resultando em uma transformação intermediária nas fases do aço SAE 1045. A presença de bainita e mesmo perlita na metalografia do aço temperado em óleo mostra que o resfriamento foi lento o suficiente para que o resfriamento transitasse "dentro" do joelho da curva TTT. O mesmo ocorre com a solução polimérica mas nessa está menos presente o microconstituinte perlita e observa-se característica formação da bainita. Água e salmoura, meios de têmpera mais severos, apresentam agulhas de martensíta que são responsáveis pela elevação da sua dureza.

Conclui-se que a transformação da austenita em martensíta foi mais presente na solução polimérica do que no óleo, muito embora o resfriamento tenha sido significativamente mais brando do que na água pura.

Os valores de dureza para a amostra temperada em salmoura não foram satisfatórios e, observando a fotografia desta amostra, pode se constatar que a oxidação superficial impediu que o contato com o meio de têmpera fosse efetivo.

\section{Agradecimentos}

Aos professores Dr. Jan Vatavuk e Msc Leonardo Calicchio, pelos conhecimentos transferidos e prestatividade na orientação desse trabalho.

À Universidade Presbiteriana Mackenzie, por disponibilizar os laboratórios e equipamentos os tratamentos térmicos e ensaios posteriores. 


\section{REFERÊNCIAS}

1 CHIAVERINI, V. (2012) "Aços e Ferros Fundidos".

2 TOTTEN, G.E., DOSSET, J.L. and KOBASKO, N.I. (2013) 'Quenching of Steel', ASM Handbook, Volume 4A, Steel Heat Treating Fundamentals and Processes, 2013.

3 ONAN, M. and ÜNAL, H. I. (2014) "Understanding of polymer quenchant (polyalkylene glycol) characteristic during quenching process of tool steels", Int. J. Microstructure and Materials Properties, Vol. 9, No. 1, 2014.

4 GORYUSHIN, V.V. and SHEVCHENKO, S. YU. (2010) "On the use of polymer quenchants in industry", Springer Science, Vol. 6, June, pg.26-30.

$5 \quad$ LISCIC, B. and TOTTEN, G.E. (1997) "Benefits of delayed quenching", Advanced Materials and Processes, Vol. 9, No. 97, pg.180-184. 